The provision within the patient's body of a compact power supply for the artificial heart is another major problem that has to be solved. 'It has been found impossible to use power from another muscle, because apparently no other type of muscle can withstand the constant activity that is required. ${ }^{6}$ 7 Implantation of batteries has so far proved impracticable because the large amount of power required means they must be large and frequently replaced. The size of batteries might be reduced by partially recharging them from power generated by muscular contraction. ${ }^{8} \mathrm{~J}$. C. Schuder has recently shown that sufficient electrical energy may be transmitted across the intact chest wall to drive an artificial heart by means of a radio-frequency signal and a portable external power source. $^{8}$

Replacement of the human heart is likely to become possible. Nevertheless, it must be remembered that about a third of the population die from heart disease. The philosophical and moral problems of selecting patients for treatment are thus likely to prove even more difficult than they are for continued renal dialysis.

\section{Absorption of Toxic Drugs from Burns}

Many different forms of local treatment, including the application of soluble compounds, have been recommended for burns, and local prophylaxis by some antimicrobial agents has been found to be highly effective. ${ }^{1-4}$ Though compounds of large molecular size (such as polymyxin) are not easily absorbed, sulphonamides appear readily in the blood stream when applied to extensive burns $^{3 \mathrm{~s}}$; small amounts of silver have been found in the tissues of burned patients treated with silver nitrate compresses $^{4}$; and lactosuria has been reported in patients whose burns were treated with lactose powder. Antibiotics and other agents which are considered too toxic for systemic use are often applied locally without obvious ill-effect, but the safety of this procedure depends on the nature of the compound and on the nature and extent of the lesion requiring treatment.

The risk that soluble compounds applied to burns may cause severe toxic effects is shown in a recent report ${ }^{7}$ by D. S. C. Procter, of Port Elizabeth in South Africa. During a period of 29 months he found that 36 out of 605 children admitted to a burn unit developed coma, which lasted for periods varying from one day to 38 days. The mortality in these patients was higher than expected, and coma occurred in 15 of the 30 who died. Unlike the coma which may develop in burned patients with septicaemia, bronchopneumonia, or electrolyte imbalance, the condition described by Procter appeared in patients who were not suffering from general illness or fever. Initially these patients developed irritability, and this was followed by apathy and by coma.

1 Jackson, D. M., Lowbury, E. J. L., and Topley, E., Lancet, 1951, 2,

Moyer, C. A., Brentano, L., Gravens, D. L., Margraf, H. W., and Monafo, W.' W., Arch. Surg., 1965, 90, 812.

- Moncrief, J. A., Switzer, W. E., Order, S. E., and Mills, W., f. Trauma, 1965, 5, 601.

- Cason, J. S., Jackson, D. M., Lowbury, E. J. L., and Ricketts, C. R., Brit. med. f., 1966, 2, 1288 .

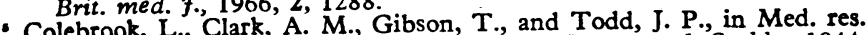
Coun. Spec. Rep. Ser. 249, Studies of Burns and Scalds, 1944, p. 16. London.

- Baar, S., and Bull, J. P., Lancet, 1952, 1, 978.

; Baar, S., and Bull, S. Afr. med. F., 1966, 40, 1116

- Procter, D. S. C., S. Atr. medictrial Toxicology, 1957, 2nd ed., p. 245. Baltimore.
During the latter the patients developed a fall in blood pressure and an increase in pulse rate and, later, oliguria, renal failure, and hypothermia.

From the distinctive pattern of symptoms and the consistently negative findings in a range of biochemical and bacteriological tests, it seemed likely that the condition was due to some component of the treatment. Coma occurred only in patients whose burns were dressed-and often appeared shortly after the application of dressings, which consisted of gauze mesh impregnated with $80 \%$ hexylene glycol. When this material came under suspicion, patients who developed coma had their dressings removed, and they recovered from coma after periods which were proportional to the duration of coma. There could be little doubt that the condition was due to absorption of hexylene glycol from the dressings-a conclusion which is supported by the similarity of the toxic signs to those recorded after ingestion of other glycols. ${ }^{8}$

In oral and parenteral therapy toxic effects of drugs are avoided by not exceeding a recommended dosage. Local therapy of burns, however, cannot be standardized by dosage in this way, and hence compounds known to have dangerous toxic effects should not be applied to extensive burns, and all agents considered for local treatment should be investigated for safety as well as clinical value.

\section{Change in New Zealand}

Next month the New Zealand Branch of the B.M.A. will become the Medical Association of New Zealand. This marks the end of a link with the B.M.A. which has existed for nearly 40 years. With the change of title comes autonomy, and a new national medical association will take its place alongside others from the Commonwealth of like history. The advance from local medical society, to B.M.A. Branch, and finally to full independence is a natural and healthy progression. It well reflects the growing strength and stature of the profession in New Zealand. The new Medical Association of New Zealand as it attains its majority can be assured of the warmest wishes and congratulations of its parent and sister associations.

Change must have been in the air at the meeting in Christchurch last February' at which these formative decisions were made. After 28 years in the chair Dr. J. O. Mercer announced his retirement from the editorship of the New Zealand Medical fournal. His has been a notable tenurethe longest since the journal first made its appearance in 1887 - and he leaves his successor, Mr. R. G. Robinson, who is a neurosurgeon (see p. 647), with a firm foundation on which to build. From being a small handbook-sized periodical of principally local interest he has turned the New Zealand Medical fournal into the elegant monthly publication now familiar to doctors all over the world. Dr. Mercer's services to New Zealand medicine have been unstinted and varied. Besides his post as director of pathology to the Wellington Hospital Board he has found time to hold high office in the New Zealand Branch and to serve on the New Zealand Medical Research Council. $\mathrm{He}$ is at the moment chairman of the Medical Council of New Zealand, the equivalent of our G.M.C. But his successful launching of the New Zealand Medical fournal upon the international scene must surely rank as highly as any of his distinguished achievements.

$$
1 \text { N.Z. med. F., 1967, 66, } 188 .
$$

